\title{
Una geografía del crimen: patrones, tendencias y percepciones urbanas
}

Isabel Avendaño Flores

Escuela de Geografía

En diciembre del 2000, en la Escuela de Geografía se presentaron públicamente dos documentos que se inscriben dentro en la Geografía Humana. Ambos conforman una unidad, se complementan y permiten repensar la ciudad de San José y su área de influencia: “Análisis espacial de la criminalidad urbana en el Área Metropolitana. Costa Rica. 1990-2000”, y “Percepción de la criminalidad urbana en el casco central de la ciudad de San José. Costa Rica. 2000”. Si en Costa Rica existiera la planificación territorial urbana, con la lectura de estos trabajos se tendría abundante material que da grandes luces para brindar una labor eficaz.

En uno de los trabajos sobresale los hechos y en el otro, la imagen que los residentes de la ciudad de San José se han construido.¿Acaso el papel del geógrafo no es el producir conocimientos útiles que expliquen el comportamiento humano en el espacio y el de analizar sus consecuencias?. El propósito de las líneas siguientes, es comentar algunas ideas que desde un punto de vista personal, parecieron interesantes de resaltar.

\section{Varios enfoques, entre lo clásico y lo pionero}

De una manera agradable a la vista y moderna con el uso de los sistemas de información geográfica, en el análisis espacial se hizo un despliegue de datos de suma importancia, los cuales permiten vislumbrar tendencias y patrones espaciales con relación al robo de medios de transporte, homicidios, violaciones sexuales y violación a la ley de sicotrópicos.

Si bien un lector podría ubicar el trabajo como tratado desde un enfoque clásico, descriptivo-explicativo, quedó en evidencia que los hechos son tan importantes, que sólo para poner un ejemplo, las muertes violentas han obstaculizado las mejoras del indicador esperanza de vida para los varones: ¿Es que la violencia puso el techo a la esperanza de vida de los varones en Costa Rica?. Este trabajo, por ejemplo, nos hereda una representación espacial donde si se es varón, joven, soltero y con poca instrucción, habitar 
ciertos sitios de San José constituye una amenaza para la vida. O bien, si usted habita en determinadas zonas del área metropolitana con vías de fácil acceso, posee un automóvil marca Toyota o Hyundai y con pocos recursos para implementar medidas de protección como una alarma o para tener su automóvil asegurado, es un blanco perfecto para el robo.

De una manera implícita pero pionera, en el análisis espacial de la criminalidad se realizan exploraciones muy interesantes para desarrollar una geografía del género ya que se toca la temática de la violación sexual y la de los homicidios. De la investigación se deduce que los roles que la sociedad ha asignado a los sexos, por una parte, dificultan la denuncia de actos salvajes como la violación y por otro lado, hay actos que se “dan” más un sexo que en el otro. La misma definición de violación prácticamente solo hace alusión a las mujeres, o en el caso de los homicidios, cuya ocurrencia es mayor en los hombres que en la mujeres. De modo que, en el análisis se conjugaron los roles que la sociedad nos asigna, la inconsciencia de quienes toman (imprecisión, negligencia o ignorancia) y de quienes son los supuestos dueños de los datos en las instancias correspondientes, y las pocas denuncias que se estima que se hacen debido a la doble victimización (caso de la violación sexual), para que este primer contacto con la geografía del género fuese realmente espinoso.

Otro de los aportes de este trabajo exploratorio fue descubrir que las fuentes de información en Costa Rica para desarrollar una geografía del crimen están en condiciones precarias. Definitivamente dificultan o hasta impiden hacer ciencia, describir los hechos y sistematizar las acciones. Además de contar con datos imprecisos o incompletos ¿qué otra importancia tiene el asunto de las fuentes?, Bueno es que precisamente, en el tema que nos ocupa se quiso dejar de lado las estigmatizaciones que se tienen de algunos sectores o personas de nuestra capital en torno al delito y, confrontar la percepción y la vivencia de los lugares. Sería interesante hacer trabajos interdisciplinarios donde podamos por ejemplo conocer las zonas más violentas y relacionarlas con características sociales, económicas o geográficas pero la carencia de datos obstaculiza establecer relaciones.

En muchas de las denuncias interpuestas se "olvidó" anotar por ejemplo, el sitio donde se efectuaba el delito, llámese violación sexual, homicidio o decomiso de droga, ni siquiera a escala cantonal. Igualmente se obviaron datos de suma importancia como el sexo, la edad de la víctima, la fecha y hora del crimen. La llamada cifra negra es abundante, como si fuese lo mismo que una violación sexual se diera en el parque central de San José o en el parque de Rancho Redondo en Goicoechea, en un distrito del casco central de la 
capital o en uno con un modo de vida todavía rural; o bien, que la víctima o el victimario fuesen adolescentes, de 35 años o ancianos.

El segundo trabajo se circunscribe en la geografía de la percepción, demostrándose que cada persona posee una imagen particular del hecho urbano, pero que al momento de realizar la lectura de los datos recogidos, podemos encontrar grandes similitudes aún viajando por las tres escalas geográficas que los autores tratan (inmediata, vecinal y local), en las cuales varían los actores; así como las realidades negativas y positivas. Se retoman tres escalas geográficas, tres caparazones como los llaman Bailly y Beguin (1992) entre el "yo y el mundo", espacios cargados de gran contenido económico y psicosocial donde las personas desarrollan la territorialidad, por tanto, hacen valer sus intereses.

Si bien es cierto, que la geografía de la percepción se ha venido trabajando de manera dispersa en la Escuela de Geografía de la Universidad de Costa Rica a lo largo de las últimas dos décadas, de nuevo surgen algunas ideas en torno a los espacios que nos rodean, en especial aquel que hoy día es el asentamiento poblacional más denso, numeroso y más importante social, económico y político de Costa Rica. Este trabajo aunque no-pionero en la rama de la percepción ambiental en Costa Rica, lo es bajo el punto de vista de uno de los temas que ha cobrado más víctimas y ha llamado la atención en el ámbito nacional, regional y mundial, cual es la criminalidad; en este caso, la criminalidad urbana.

\section{El crecimiento urbano y la criminalidad crecen como manchas de aceite}

Para el caso del Área Metropolitana, ambos trabajos dejan en evidencia que existe una estrecha relación entre el proceso de urbanización y la criminalidad. La última constituye un factor que contribuye al crecimiento de la mancha urbana. De las entrevistas, las personas observan como sus vecinos, aquellos que cuentan con recursos económicos buscan en la periferia urbana un sitio de refugio ante el crimen. Lo cual es natural, puesto que los datos demostraron que la agresividad y la cantidad de actos delictivos decrecen del centro hacia la periferia, en este caso por el plano de la ciudad, en forma de óvalos centrífugos. Por ahora, mientas más alejado viva alguien del centro de San José, mayor seguridad tiene de ser acosado por algún delito contra la propiedad que es el crimen más común. Dicha afirmación constituye una percepción de los residentes de San José que es confirmada por la cantidad de eventos delictivos. 
De manera indirecta, no como factor decisivo, la violencia contribuye al desplazamiento de los centros de compras, edificios de oficinas y actividades de ocio hacia las zonas periféricas. Por supuesto que en la localización se combinan diferentes criterios como unos buenos niveles de accesibilidad, un menor coste de la tierra (relación centro-periferia) y la generalización del automóvil. Claro, paradójicamente, ha existido una importante expansión del consumo y al mismo tiempo, una contracción del poder adquisitivo de la mayoría, lo que implica que una mayoría está siendo presionada por hábitos de consumo de muchos, que para algunos especialistas implicaría propensión al delito por parte grupos marginados.

\section{Continua el proceso hacia una ciudad cada vez más segregada}

Están ocurriendo cambios en el uso del espacio que cuestionan las teorías clásicas urbanas, donde la ciudad centralizada tiende a una ciudad policéntrica, resultado del desarrollo de estos nuevos centros comerciales y cuyo tejido urbano se complica. De modo que el espacio geográfico urbano percibido y vivido se encamina hacia una ciudad diseminada de la que cada vez tenemos menos idea dónde termina, dónde empieza o en qué lugar estamos, de una bajísima experiencia del conjunto de nuestra ciudad.

Tome en cuenta el lector, que en esta segregación de la ciudad desde el enfoque de la criminalidad, vivir en un sector popular o en uno de condición socioeconómica acomodada tiene sus ventajas y desventajas. Los sectores populares están sometidos a ciertos tipos de delitos como los homicidios y al arduo trabajo de la policía haciendo decomisos para evitar el tráfico de cierto tipo de drogas calificadas como "bajas". Y, en los sectores adinerados, al robo de automóviles y al tráfico de drogas al que solo puede acceder una persona con dinero con ventajas para camuflarse. Del trabajo sobre análisis espacial se deduce que el patrón en el robo de automóviles es concentrado y obedece a un factor socioeconómico.

Datos sobre el crecimiento urbano indican que la mancha urbana creció en un 80\% en la década de 1990, con el gran inconveniente que ha sido de forma caótica, hacia todas direcciones y sin planificación. Esto ha tenido un efecto negativo en la economía de algunos barrios céntricos y muy productiva para algunos con la construcción de infraestructura de alto costo en centros comerciales que ofrecen todo tipo de bienes y servicios y donde el comercio al por menor es la norma. 


\section{La criminalidad está replegando la familia en fortalezas}

En el ámbito de las escalas geográficas: la inmediata, por ejemplo, las viviendas son hoy verdaderas cárceles preventivas para las familias y no precisamente porque un tribunal sentencie prisión residencial. Las verjas, los portones, el amurallamiento, las alarmas, los ojos de gato, el alambre navaja y hasta los perros han provocado que en nuestras casas se viva hacia adentro, hacia el interior. Un estilo urbano de otras culturas, no propio de nuestra herencia latina. Inclusive, en el análisis vecinal, se deja entrever como los hechos delictivos están provocando una individualización porque es la forma de sentirse seguros.

Además, se ha construido un paisaje urbano abigarrado de barrotes y alambres, que afean las casas, el vecindario y por ende, la ciudad. Medidas de protección que van en desarmonía con el paisaje arquitectónico de muchos sectores capitalinos. Mencionan en el trabajo de percepción que la gestión de los ocupantes “... genera una diversidad visual de fachadas con el común denominador del encierro...".

\section{Socavamiento del contacto vecinal: Un problema social}

Los vecindarios especialmente los barrios que son considerados modos de vida de los pobladores, sitios que proporcionan identidad a los vecinos, que constituyen puntos de referencia fuertemente vinculados con la noción de territorialidad e indicios de identidad colectiva, entre otras características morfológicas y funcionales, están siendo fuertemente medrados por la criminalidad. Quedó claramente demostrado como a escala vecinal, las personas perciben que la delincuencia esta obstaculizando la convivencia. Las personas perciben que justamente cruzando el umbral de la casa, comienza la inseguridad.

Estamos ante un grave problema, puesto que el vecindario constituye la entidad básica de sociabilidad y de las relaciones personales, es el lugar donde individuos y familias se conocen. El efecto vecinal es uno de los principales mecanismos de difusión espacial de novedades y cultura, entre otros. Y, se ha probado como son las mujeres las que inicialmente crean importantes nexos con las vecinas, resultado de encuentros casuales pero numerosos en comparación con los hombres pero las que precisamente se sienten más amenazadas y vulnerables.

Desde el punto de vista de las instancias estatales, se ve en la organización comunal una alternativa para enfrentar el crimen y devolver la seguridad al ciudadano. Sin embargo, los trabajos nos dieron como 
resultado que aún cuando la relación vecinal es buena, la organización comunal es inexistente y, seguridad y organización van de la mano. En este sentido, las nuevas políticas estatales de organización comunitaria contra el crimen prácticamente estarían dando palos de ciego. No existe ningún vecindario en el casco central de la ciudad de San José, inscrito en el Programa de Seguridad Comunitaria del Ministerio de Seguridad Pública.

\section{Impedimento para la apropiación de los espacios públicos}

Estamos ante una paradoja, porque aún cuando la administración pública continúe invirtiendo importantes sumas de dinero en la renovación de parques, por ejemplo, el miedo a la violencia está alejando a los josefinos de los espacios públicos, de las calles, de aquellos sitios que históricamente jugaban un papel de suma importancia en el acontecer de una comunidad o de un vecindario como espacios de reunión, intercambio vecinal o simplemente como zonas de tránsito.

Hoy, las personas los perciben como riesgosos y si es por el puro placer, se evita recorrerlos. Sectores de la avenida central, para citar un ejemplo, son de las varias zonas que han sido pensadas para que los transeúntes circulen parsimoniosos, para que se detengan a conversar, dice Néstor García Canclini (1999), como prolongaciones de sus patios. Actualmente, son invadidas y conquistadas por delincuentes.

Queda un sinsabor, una dualidad que los tomadores de decisiones deben repensar. Por un lado, se propugna que la sociedad civil tenga una actitud más agresiva ante lo que sucede a su alrededor, que participe activamente y deseche la idea del Estado paternalista; pero a su vez, los hechos delictivos provocan la reacción contraria: ¡cada cual en su casa y Dios en la de todos!.

\section{La ciudad de San José: un sitio de riesgo}

Todo lugar, además de sus funciones económicas, históricas y sociales, es también un espacio psicológico, un territorio que detenta una carga de significados. Argumenta Peter Gould (1935) que la gente reacciona frente al entorno percibido; su comportamiento resulta más un reflejo de las imágenes que se forma del ambiente social y físico que de sus verdaderos caracteres, la analogía siguiente muestra el paso de un comportamiento simple a uno complejo sólo debido a la complejidad del medio en que se desarrolla. Por ejemplo, una hormiga que después de buscar alimento regresa al hormiguero a través de una playa que ha 
sido ondulada por el oleaje. Si se representan sus movimientos sobre un mapa, la trayectoria parece sumamente complicada, ya que cambia de dirección una y otra vez entre las ondulaciones de la arena que en relación con su tamaño son enormes y le tapan la vista. Sin embargo, el comportamiento de la hormiga es muy simple: alcanzar su meta, esto es llegar al hormiguero lo antes posible. Su tortuoso camino no expresa este simple y rectilíneo comportamiento, sino que deriva exclusivamente de la complejidad del medio en el que se desarrolla.

Del mismo modo, en términos humanos, el comportamiento espacial de los pobladores de la ciudad de San José ha demostrado que está muy afectada por una zonificación invisible originada por fuerzas ambientales percibidas que subyacen en el área. Los habitantes también evitan los lugares escarpados y peligrosos, y buscan los valles abrigados y más seguros; esta superficie de percepción es conocida como mapas mentales. Los lugares atractivos para atravesar o vivir son las elevaciones y los sectores riesgosos, poco atractivos, menos apreciados: las depresiones. Pues bien, en la lectura de los hechos y de la percepción quedan claros los sitios inseguros, intransitables desde el punto de vista de la violencia. Según la investigación, si un extranjero le preguntara a un josefino por donde transitar para conocer de forma segura San José, contestaría que haciendo uso del helicóptero y de cualquier forma, evitar la noche... Un $90 \%$ de las personas entrevistadas ven en la ciudad capital un sitio inseguro y muy inseguro, sin importar sexo, nivel de instrucción o edad.

Al estudiar las nociones subjetivas de la realidad urbana, se ha visto como la criminalidad en el centro de San José está provocando que varíen las sendas urbanas, aquellos conductos usuales por el entrevistado para desplazarse en el interior del núcleo urbano, en su entorno local. ¿Cómo es posible que las personas consideren seguro sólo el interior de las iglesias y sumamente inseguro su alrededor?

\section{Los delincuentes: Nuevos agentes urbanos}

Parece ser que, dentro de los agentes urbanos debemos de agregar a los delincuentes, en virtud de que indirectamente están participando de la configuración de la ciudad: empujando algunos sectores a ciertos más ventajosos (mas seguros), a otros a áreas críticas (sitios inseguros) o creando espacios de disputa. Coadyuva, una percepción de la gente de que la policía estatal es incapaz de brindar una protección eficiente; cuya honestidad es cuestionable. Sumado, la total desorganización entre residentes y fuerzas 
policiales estatales y una policía privada que presta servicio con agentes que predominantemente son ilegales puesto que no se encuentran debidamente registrados, sin licencia para tal función y que prefieren prestar servicio al comercio más que a la zonas residenciales, quedando las últimas a la deriva del crimen.

\section{¿Qué debemos esperar?}

Del trabajo se deduce la que violencia crece en el mismo sentido que la urbanización, donde quedó además demostrado que tendemos hacia una sociedad cada vez más agresiva y con delincuentes cada vez más jóvenes. Una sociedad costarricense con tendencias al envejecimiento pero una violencia con tendencias al rejuvenecimiento y es justo en el centro de San José donde prevalece una población de tercera edad y quienes quedan expuestos a los delincuentes, según los hechos y según su autopercepción.

\section{Síntesis: Una geografía del crimen para una mejor sociedad}

A manera de síntesis, investigaciones como las que en estas notas se reseñaron tienen un alto potencial en la búsqueda de una mejor sociedad. Un modelo hipotético posible para relacionar las disciplinas de la geografía sería suponer, que un crimen ocurre en una ciudad (espacio definido), en donde la sociedad presenta ciertas características culturales (geografía cultural), poblacionales (geografía de la población), que tienen raíces históricas (geografía histórica). Además, un modelo económico determina la calidad de vida de sus habitantes (geografía económica), generando condiciones que podrían influir para que un individuo actúe patológicamente en contra de la sociedad o uno de sus miembros (geografía médica) y complementado con aquella rama que estudie las condiciones del medio cultural y físico, buscando darle una solución al problema. (geografía del bienestar o del malestar). Y, utilizando modernos sistemas cartográficos ... existe un alto potencial de aporte social.

Si bien la geografía es una ciencia espacial, en el caso de la criminalidad puede aportar mucho, porque no se aboca únicamente a brindar un mapa de delitos donde estén localizados los crímenes y los ciudadanos puedan protegerse más eficientemente sino que por lo que analiza en la búsqueda de relaciones de causaefecto, permite dar soluciones preventivas, por ende, evitar la repetición de crímenes. 


\section{Bibliografía}

- Bally, A. Y Beguin, H. Introducción a la geografía humana. Barcelona: Masson, S.A.

- Estado de la Nación

- García 1999. Imaginarios urbanos.

- Gould, P. Las imágenes mentales del espacio geográfico. En: Gómez, J.; Muñoz, J. Y Ortega, N. 1988. El pensamiento geográfico. Madrid: Alianza Universidad Textos. Pág. 477-484.

- Grupo ADUAR, et. al. 2000. Diccionario de geografía urbana, urbanismo y ordenación del territorio. Barcelona: Editorial Ariel S.A. 